\title{
Evidenciação Ambiental: uma análise dos relatórios de sustentabilidade da Usina Hidrelétrica Itaipu com base na Global Reporting Initiative - GRI \\ Environmental Disclosure: an analysis of the sustainability reports of the Itaipu Hydroelectric Plant based on the Global Reporting Initiative - GRI
}

\author{
Regiane Valejo Maciel ${ }^{1}$ \\ Carlos Jaelso Albanese Chaves ${ }^{2}$ \\ Giuliano Oliveira de Macedo $^{3}$
}

\section{Resumo}

Considerando que o setor de hidrelétricas causa impactos ambientais de larga escala e que a evidenciação ambiental vem se tornando cada vez mais relevante para as organizações, a presente pesquisa teve por objetivo avaliar a qualidade da evidenciação ambiental praticada nos relatórios de sustentabilidade da Usina Hidrelétrica Binacional Itaipu. Quanto à abordagem, este estudo fundamenta-se na pesquisa qualitativa, e quanto ao objeto, este estudo se classifica como uma pesquisa documental. Para atingir o objetivo desta pesquisa, a coleta dos dados foi proporcionada pelos relatórios de sustentabilidade da Usina Hidrelétrica Itaipu do período de 2014 a 2019, a partir da confrontação dos princípios apresentados pela Global Reporting Initiative para a elaboração do relatório com o conteúdo dos relatórios divulgados pela Itaipu. A análise dos relatórios indica que a Itaipu apresentou falhas quanto a aderência do princípio "comparabilidade", ao omitir informação sobre os valores investidos nos projetos analisados, fazendo com que a leitura do stakeholder ficasse prejudicada, entretanto, é possível identificar que a Itaipu buscou manter-se alinhada com os demais princípios analisados. O presente estudo contribuiu por buscar preencher a lacuna sobre a análise de evidenciação ambiental de uma organização de relevância social como a Itaipu Binacional.

Palavras-chaves: Desenvolvimento sustentável. Indicadores ambientais. Sustentabilidade. Setor hidrelétrico.

\begin{abstract}
Considering that the hydroelectric sector causes large-scale environmental impacts, and that environmental disclosure is becoming increasingly relevant for organizations, this research aimed to evaluate the quality of environmental disclosure practiced in the sustainability reports of the Binational Itaipu Hydroelectric Power Plant . As for the approach, this study is based on qualitative research, and as for the object, this study is classified as documentary research. To achieve the objective of this research, data collection was provided by the sustainability reports of the Itaipu Hydroelectric Power Plant from 2014 to 2019, based on the confrontation of the principles presented by the Global Reporting Initiative guidelines with the content of the reports disclosed by Itaipu. The analysis of the reports indicates that Itaipu failed to adhere to the "comparability" principle, by omitting information on the amounts invested in the projects analyzed, causing the stakeholder reading to be impaired, however, it is possible to identify that Itaipu sought to maintain aligned with the other principles analyzed. This study contributed by seeking to fill the gap on the analysis of environmental disclosure in an organization of social relevance such as Itaipu Binational.
\end{abstract}

Keywords: Sustainable development. Environmental indicators. Sustainability. Hydroelectric Sector.

Manuscript first received/Recebido em: 30/10/2020 Manuscript accepted/Aprovado em: 15/12/2021

\footnotetext{
${ }^{1}$ Graduada em Ciências Contábeis pela Universidade Estadual de Mato Grosso do Sul. Ponta Porã, Mato Grosso do Sul, Brasil. E-mail: regianevalejomaciel@gmail.com.

${ }^{2}$ Doutor em Administração. Professor da Universidade Estadual de Mato Grosso do Sul (UEMS), Ponta Porã, Mato Grosso do Sul, Brasil. E-mail: jaelso.chaves@hotmail.com

${ }^{3}$ Graduado em Ciência da Computação pela Universidade Federal de Mato Grosso do Sul, Ponta Porã, Mato Grosso do Sul, Brasil. E-mail: giuliano.programador@gmail.com
} 


\section{INTRODUÇÃO}

As mudanças climáticas podem ser consideradas o desafio mais complexo pelo qual a humanidade irá passar, devido a este fator, na contemporaneidade, as questões ambientais e o desenvolvimento sustentável vêm se tornando cada vez mais relevantes para a sociedade. Tais questões são notáveis graças às transformações que o meio ambiente sofreu e sofre em função do processo de globalização (Tinoco \& Robles, 2006).

Abordar o meio ambiente e como é afetado traz à mente o conceito de desenvolvimento sustentável, que pode ser definido como a capacidade que uma geração tem de consumir recursos sem afetar as próximas gerações (Brundtland, 1991). A preocupação com o desenvolvimento sustentável iniciou nos anos 70, como apontado por Romeiro (2012), visando entender como manter o crescimento econômico e, ao mesmo tempo, manter boas práticas sociais e ambientais.

Apesar de ter levado certo tempo e ainda caminhar devagar, a preocupação com a utilização dos recursos naturais e como preservá-los começou a ganhar espaço também no meio empresarial. Essa preocupação deve se manifestar de forma prática, mas como uma empresa pode evidenciar que está tendo (ou buscando ter) um compromisso com a área ambiental? Como ir além da preocupação com demonstrativos de resultados econômicos?

A contabilidade possui como objetivo fornecer informações sobre a entidade, visando auxiliar na tomada de decisões adequadas, apesar de no princípio a contabilidade fornecer apenas informações financeiras para seus usuários, com o passar dos anos surgiram novos usuários e novas demandas das entidades, criando uma necessidade de que a entidade relatasse não só o desempenho econômico como também o social e ambiental (Tinoco \& Kraemer, 2011).

A evidenciação de informações ambientais através de relatórios é uma maneira das organizações divulgarem para os stakeholders o seu desempenho nesta esfera, a divulgação ambiental é em grande parte uma atividade voluntária, destaca-se a Global Reporting Initiative (GRI), organização que publica padrões e documentos de orientação para elaboração de relatórios de sustentabilidade (Bebbington et al., 2021).

A GRI fornece as diretrizes mais detalhadas e estruturadas a serem seguidas pelas organizações, através de indicadores ambientais com padrões de divulgação detalhados que fornecem orientação sobre como uma organização deve relatar o tópico, e que tipo de informação qualitativa e quantitativa deve ser fornecida, entretanto, não se espera que as organizações incluam todos os indicadores em seus relatórios, devendo realizar uma avaliação de materialidade para identificar os mais significativos (Bebbington et al., 2021).

As organizações possuem controle substancial sobre quais informações são definidas como materiais e o escopo de evidenciação do relatório, embora esta avaliação deva ser um procedimento neutro e técnico, Puroila e Makela (2019) destacaram como a análise da materialidade pode ser vista como uma análise enviesada, podendo ter implicações sobre a forma como a sustentabilidade organizacional é apresentada. 
As diretrizes do relatório de sustentabilidade deveriam assegurar a qualidade das informações apresentadas no relatório, entretanto, em um estudo realizado por Motta, Mazza e Oliveira (2011, p. 78), foi identificado que "no que diz respeito aos indicadores ambientais, cerne deste estudo, há mais uma vez a omissão de dados essenciais e obrigatórios", Bebbington et al. (2021) também verificaram que características desejáveis em um relatório, tais como, comparabilidade, exatidão, clareza, entre outras, costumam não ser apresentadas, isso está ligado ao fato de que a evidenciação através de relatórios ambientais costuma ser uma prática majoritariamente voluntária, com a entidade que relata tendo controle sobre o que está incluído no relatório.

Diante da contextualização e problematização apresentada em relação à sustentabilidade e a qualidade das informações divulgadas em relatórios de sustentabilidade, o presente artigo tem por objetivo avaliar a qualidade da evidenciação ambiental praticada nos relatórios de sustentabilidade da Usina Hidrelétrica Binacional Itaipu. Para atingir o objetivo desta pesquisa, a coleta dos dados foi proporcionada pelos relatórios de sustentabilidade da Usina Hidrelétrica Itaipu do período de 2014 a 2019, a partir da confrontação dos princípios apresentados pela GRI para a elaboração do relatório com o conteúdo dos relatórios divulgados pela Itaipu.

Conforme apontado por Queiroz et al. (2013, p. 2775) as usinas hidrelétricas "influenciam diretamente no meio ambiente devido à construção das represas, que provocam inundações em imensas áreas de matas, interferindo no fluxo de rios, destroem espécies vegetais, prejudicam a fauna, e interferem na ocupação humana". Devido ao impacto de tal magnitude, é fundamental que a companhia invista em meios de preservar o meio ambiente ou, ao menos, amenizar tais impactos. Assim, o relatório de sustentabilidade mostra-se como uma tentativa relevante de evidenciar os investimentos e esforços para seus stakeholders.

A justificativa para a escolha da Usina Itaipu como objeto da análise deve-se ao fato da mesma ser considerada a maior hidrelétrica considerando sua produção acumulada (Itaipu binacional, 2019a), além do discurso sobre responsabilidade socioambiental estar incluído em sua missão, visão e valores. A usina hidrelétrica adota o modelo da GRI para a divulgação de seus relatórios.

A relevância deste trabalho dá-se pela análise de relatórios ambientais e seus variados modelos, ser uma área em que mais pesquisas são necessárias (Bebbington et al., 2021), e por preencher a lacuna sobre a análise de evidenciação ambiental de uma organização de relevância social como a Itaipu Binacional.

\section{REFERENCIAL TEÓRICO}

\subsection{Evidenciação Ambiental}

Para Tinoco e Kraemer (2011), a evidenciação ambiental tem como objetivo divulgar informações sobre o desempenho ambiental da entidade, ocorrendo através de relatórios socioambientais ou notas explicativas. A divulgação de relatórios com informações 
ambientais iniciou-se na década de 90, surgindo à medida que as questões ambientais deixaram de ser uma inquietação exclusiva dos cientistas e ambientalistas e passasse também a alcançar a sociedade, o governo e, principalmente, a iniciativa privada (Gray \& Bebbington, 2001, Ferreira, 2011).

A contabilidade possui como objetivo fornecer informações sobre a entidade, visando auxiliar na tomada de decisões, devendo considerar também as informações ambientais em seus sistemas de gestão, ao contribuir com o desenvolvimento de relatórios e avaliações de desempenho, identificar e procurar corrigir conflitos entre o aspecto convencional (financeiro) e ambiental e, encontrar maneiras de incorporar a sustentabilidade na organização (Gray \& Bebbington, 2001).

A evidenciação de informações ambientais por parte das empresas pode ocorrer de maneira compulsória, em decorrência de exigências legais, ou de maneira voluntária. A motivação para a evidenciação voluntária é diversa, entre as razões é possível identificar a pressão pública, atrair investidores, melhorar a reputação, transmitir uma imagem positiva, cumprir com as expectativas da comunidade, ou melhorar o desempenho econômico (Silva et al., 2018).

Mota, Mazza e Oliveira (2011) analisaram a divulgação dos indicadores de cunho ambiental nos relatórios de empresas que publicaram relatórios nos padrões da GRI no ano de 2009. Os autores concluíram que "embora as empresas se autodeclarem estrategicamente sustentáveis, não possuem em suas visões declaradas menção ao desenvolvimento sustentável" (p. 78), também se percebeu que nem todos os princípios determinados pela GRI são seguidos na elaboração dos relatórios.

Sucena e Marinho (2019) avaliaram o nível da evidenciação ambiental praticada nos relatórios de sustentabilidade das indústrias cervejeiras brasileiras, através da análise dos relatórios de sustentabilidade dos anos de 2011 a 2013 das empresas brasileiras: Ambev, Brasil Kirin, Grupo Petrópolis e Heineken Brasil e, das representantes internacionais, AB InBev, SABMiller e Heineken Holanda. O estudo identificou a baixa divulgação de indicadores GRI, ausência de verificação externa do documento, e a falta de correlação financeira dos indicadores ambientais.

Oliveira et al. (2020) analisaram o nível de divulgação ambiental das empresas do setor elétrico dos países do BRICS (Brasil, Rússia, Índia, China e África do Sul) levando em consideração o recomendado pelas diretrizes da GRI e pelas orientações da UNCTAD (United Nations Conference on Trade and Development). Foi identificado que as corporações sediadas na África do Sul, no Brasil e na Rússia foram as que tiveram maior nível de evidenciação ambiental, enquanto as empresas indianas e chinesas apresentaram menor nível de divulgação dos indicadores ambientais GRI.

Um estudo desenvolvido por Gaudencio et al. (2021) analisou como os relatórios de sustentabilidade do ano de 2015 de quatro petroleiras e uma prestadora de serviços no segmento de óleo e gás que atuam no Brasil aderem aos indicadores essenciais específicos das categorias econômica, ambiental e social, propostos pela versão G4 das diretrizes GRI, o estudo concluiu pela falta de aderência total às diretrizes GRI. 


\subsection{Desenvolvimento Sustentável e Relatórios de Sustentabilidade}

Em 1987, foi publicado o Relatório Brundtland, também conhecido como Nosso Futuro Comum, pela ex-Primeira-Ministra da Noruega, Gro Harlem Brundtland. É nesse relatório que o conceito de desenvolvimento sustentável é trazido como "[...] aquele que atende às necessidades do presente sem comprometer a possibilidade de as gerações futuras atenderem a suas próprias necessidades" (Brundtland, 1991, p. 46), sendo essa a conceituação mais comumente utilizada.

O papel das empresas e sua relação com o desenvolvimento sustentável é extremamente importante, visto que a prática empresarial sustentável faz com que a entidade contribua para a preservação ambiental, gerando benefícios para a sociedade, e com que se posicione positivamente perante os stakeholders, melhorando a imagem da empresa e sua credibilidade (Tinoco \& Kraemer, 2011).

O relatório de sustentabilidade é uma demonstração que visa evidenciar informações contábeis, econômicas, ambientais e sociais da entidade aos mais diferenciados usuários. Essa demonstração surgiu nos anos 70, na França, oriunda da pressão feita por movimentos sociais que ocorriam na época. Após esse acontecimento, o demonstrativo espalhou-se pela Europa e, posteriormente, para os demais continentes (Tinoco \& Kraemer, 2011).

É um demonstrativo utilizado pelas empresas para evidenciar seu compromisso com o desenvolvimento sustentável e a transparência com o público, pois evidencia os impactos causados pela entidade, mostrando que ela possui compromisso não só com os proprietários e acionistas, mas também com a sociedade (Igarashi et al., 2010, GRI, 2006).

O conteúdo do relatório é composto por informações qualitativas e quantitativa que visam evidenciar três dimensões (Tinoco \& Kraemer, 2011, GRI, 2006): a) Econômica: refere-se à condição econômica da entidade e aos seus impactos sobre os sistemas econômicos; b) Ambiental: impactos da organização sobre sistemas naturais vivos e nãovivos, incluindo ecossistemas, terra, ar e água; c) Social: impactos da organização nos sistemas sociais nos quais atua.

A dimensão ambiental, abordada nesta pesquisa, possui desafios particulares em sua evidenciação, enquanto os relatórios financeiros divulgados pela maioria das organizações apresentam uma padronização, nos relatórios ambientais essa uniformidade não existe (Bebbington et al., 2021).

Questões ambientais relevantes variam dependendo do segmento de atuação da empresa, fazendo com que as organizações tenham certa liberdade em relação à forma como evidenciam e quais informações evidenciam, a partir deste desafio houve o surgimento de organizações que buscam padronizar e guiar as informações reportadas (Bebbington et al., 2021).

Bebbington et al. (2021) apontam características comuns, que muitas vezes são consideradas características de um relatório ambiental de alta qualidade: 
Quadro 1: Características da Evidenciação Ambiental

\begin{tabular}{|c|c|c|}
\hline Característica & Descrição & Pontos a considerar \\
\hline Exatidão & $\begin{array}{l}\text { As informações em um relatório } \\
\text { devem ser suficientemente precisas } \\
\text { e detalhadas para permitir que os } \\
\text { leitores avaliem o desempenho de uma } \\
\text { organização. }\end{array}$ & $\begin{array}{l}\text { As organizações às vezes são } \\
\text { vagas ao apresentar informações } \\
\text { negativas. Os gráficos e tabelas } \\
\text { estão estruturados corretamente ou } \\
\text { foram distorcidos ou distorcidos? }\end{array}$ \\
\hline Equilíbrio & $\begin{array}{l}\text { Um relatório deve incluir aspectos } \\
\text { positivos e negativos para que os } \\
\text { usuários possam avaliar o desempenho } \\
\text { geral da organização. }\end{array}$ & $\begin{array}{l}\text { As organizações costumam enfatizar } \\
\text { informações positivas. Padronizações } \\
\text { e práticas de verificação externa } \\
\text { podem ajudar na obtenção de } \\
\text { relatórios mais equilibrados. }\end{array}$ \\
\hline Clareza & $\begin{array}{l}\text { As informações em um relatório devem } \\
\text { ser apresentadas de forma clara, } \\
\text { compreensível e acessível. }\end{array}$ & $\begin{array}{l}\text { Os grupos de usuários possuem } \\
\text { variado conhecimento e capacidade } \\
\text { de entender as informações. O que } \\
\text { é complexo para alguns pode ser } \\
\text { evidente e simplista para outros. }\end{array}$ \\
\hline Comparabilidade & $\begin{array}{l}\text { As informações devem ser selecionadas, } \\
\text { compiladas e relatadas de forma } \\
\text { consistente. Permitindo a análise de } \\
\text { mudanças ao longo do tempo e em } \\
\text { relação a outras organizações, sempre } \\
\text { que possível }\end{array}$ & $\begin{array}{l}\text { Estruturas de relatórios podem } \\
\text { ajudar fornecendo práticas padrão. } \\
\text { A organização fornece informações } \\
\text { de anos anteriores para permitir } \\
\text { que o leitor veja tendências e } \\
\text { desenvolvimentos facilmente? }\end{array}$ \\
\hline Confiabilidade & $\begin{array}{l}\text { As informações relatadas devem ser } \\
\text { baseadas em processos confiáveis, } \\
\text { que também podem estar sujeitos a } \\
\text { avaliação independente. }\end{array}$ & $\begin{array}{l}\text { Além das informações relatadas, } \\
\text { também é relevante discutir como as } \\
\text { informações foram coletadas. }\end{array}$ \\
\hline $\begin{array}{l}\text { Inclusão das partes } \\
\text { interessadas } \\
\text { (stakeholders) }\end{array}$ & $\begin{array}{l}\text { Uma organização deve identificar e } \\
\text { envolver as partes interessadas e } \\
\text { discutir como ela respondeu às suas } \\
\text { expectativas e interesses. }\end{array}$ & $\begin{array}{l}\text { Os grupos de partes interessadas } \\
\text { podem ter expectativas muito } \\
\text { diferentes. Diferentes formas de } \\
\text { evidenciação têm diferentes públicos, } \\
\text { que podem ter expectativas diferentes. }\end{array}$ \\
\hline Periodicidade & $\begin{array}{l}\text { Os relatórios devem ser publicados em } \\
\text { um cronograma regular e em tempo hábil } \\
\text { para permitir que os usuários do relatório } \\
\text { tomem decisões informadas }\end{array}$ & $\begin{array}{l}\text { Os relatórios divulgados em sites } \\
\text { geralmente podem ser mais } \\
\text { tempestivos, mas um ciclo de } \\
\text { relatórios anual e regular pode ter } \\
\text { outras vantagens. Periodicidade } \\
\text { não é apenas uma questão de } \\
\text { velocidade, mas também de } \\
\text { regularidade. }\end{array}$ \\
\hline
\end{tabular}

Fonte: Adaptado de Bebbington et al. (2021, p. 113)

Apesar das características listadas, os relatórios ambientais costumam falhar ao apresentá-las, isso está ligado ao fato de que os relatórios ambientais costumam ser uma prática majoritariamente voluntária, com a entidade que relata tendo controle substancial sobre o que está incluído no relatório (Bebbington et al., 2021).

Bebbington et al. (2021) afirmam que "uma organização e suas várias partes interessadas podem, por exemplo, compreender a precisão e o equilíbrio de maneiras muito diferentes e, portanto, ter expectativas diferentes sobre o que deve ser relatado e como deve ser relatado" (p. 114). Os autores sugerem que a verificação externa pode ser uma forma para melhorar a qualidade dos relatórios ambientais, já que tal declaração de terceiros poderia dar aos leitores mais confiança nas informações relatadas. 


\subsection{Global Reporting Initiative}

À medida que os relatórios ambientais se tornaram mais comuns, houve várias tentativas de estabelecer estruturas para orientar a divulgação, entre elas temos a GRI, fundada em 1997, o relatório tem como objetivo proporcionar informações para que sejam tomadas decisões que criam benefícios sociais, ambientais e econômicos (Bebbington et al., 2021). A GRI tem sido um dos modelos mais influentes e difundido para relatórios de sustentabilidade, publicando padrões e documentos de orientação com uma abordagem para promover e apoiar o desenvolvimento de relatórios de sustentabilidade (Bebbington et al., 2021).

Para evidenciar a dimensão ambiental, o relatório possui os "indicadores ambientais" que evidenciam o desempenho obtido e demais informações relevantes, em nove aspectos diferentes: materiais; energia; água; biodiversidade; emissões; efluentes e resíduos; produtos e serviços; conformidade; transporte; e geral (GRI, 2006). Através destes indicadores, o relatório pode oferecer aos stakeholders uma evidenciação equilibrada e confiável do desempenho ambiental da organização (Tinoco \& Kraemer, 2011).

Os indicadores ambientais possuem normas de divulgação detalhadas que fornecem orientações sobre como uma organização deve evidenciar o tópico, como deve ser avaliada e que tipo de informação qualitativa e quantitativa deve ser fornecida, no entretanto, não se espera que as organizações incluam todos os indicadores em seus relatórios, devendo realizar uma avaliação de materialidade para identificar os mais significativos (Bebbington et al., 2021).

Quadro 2: Nomenclatura dos indicadores ambientais

\begin{tabular}{|c|c|c|}
\hline Aspecto & G4 - Evidenciação & Número da evidenciação \\
\hline Materiais & G4-EN1, G4-EN2 & $301-1,301-2$ \\
\hline Energia & $\begin{array}{l}\text { G4-EN3, G4-EN4, G4-EN5, } \\
\text { G4-EN6, G4-EN7 }\end{array}$ & $\begin{array}{l}302-1,302-2,302-3,302-4, \\
302-5\end{array}$ \\
\hline Água & G4-EN8, G4-EN9, G4-EN10 & $303-1,303-2,303-3$ \\
\hline Biodiversidade & $\begin{array}{l}\text { G4-EN11, G4-EN12, G4- } \\
\text { EN13, G4-EN14 }\end{array}$ & $304-1,304-2,304-3,304-4$ \\
\hline Emissões & $\begin{array}{l}\text { G4-EN15, G4-EN16, G4- } \\
\text { EN17, G4-EN18, G4-EN19, } \\
\text { G4-EN20, G4-EN21 }\end{array}$ & $\begin{array}{l}305-1,305-2,305-3,305-4, \\
305-5,305-6,305-7\end{array}$ \\
\hline Efluentes e resíduos & $\begin{array}{l}\text { G4-EN22, G4-EN23, G4- } \\
\text { EN24, G4-EN25, G4-EN26 }\end{array}$ & $\begin{array}{l}306-1,306-2,306-3,306-4, \\
306-6\end{array}$ \\
\hline Produtos e serviços & G4-EN27a, G4-EN28 & $\mathrm{N} / \mathrm{A}^{\mathrm{a}}, 301-3$ \\
\hline Conformidade & G4-EN29 & $307-1$ \\
\hline Transporte & G4-EN30a & $\mathrm{N} / \mathrm{A}^{\mathrm{a}}$ \\
\hline Geral & G4-EN31 & $\mathrm{N} / \mathrm{A}^{\mathrm{b}}$ \\
\hline
\end{tabular}

Fonte: Adaptado de GRI (2021).

a divulgação dos indicadores destacados foi descontinuada para reduzir a evidenciação de conteúdo em duplicidade.

${ }^{\mathrm{b}}$ o conteúdo deste indicador foi incorporado em outros aspectos do relatório (Emissões, Efluentes e resíduos, Conformidade). 
A materialidade das informações divulgadas é subjetiva, um estudo realizado por Puroila e Makela (2019) identificou que o entendimento e implicações do conceito de materialidade são ambíguos, pois, a forma de evidenciar informações sobre o desempenho sustentável corporativo, pode ser vista como uma escolha política, incluindo julgamentos de valores, impactando o entendimento e percepção do leitor sobre o desenvolvimento sustentável corporativo.

Um fator relevante para assegurar a qualidade das informações divulgadas pelo relatório é a orientação a partir de alguns princípios determinados pelo GRI, pois desta forma o relatório pode proporcionar uma transparência efetiva e possibilitar que os stakeholders realizem uma avaliação consistente e justa da empresa (GRI, 2006). Tais princípios devem ser aplicados desde a coleta das informações até a elaboração e divulgação do relatório, os princípios são (GRI, 2006):

a) Equilíbrio: o relatório deve refletir aspectos positivos e negativos, visando permitir uma análise equilibrada do desempenho;

b) Comparabilidade: os stakeholders que utilizarem o relatório deverão poder comparar as informações sobre o atual desempenho da organização com o anterior;

c) Exatidão: as informações deverão ser precisas e detalhadas;

d) Periodicidade: o relatório deve ser publicado regularmente;

e) Clareza: as informações deverão estar disponíveis de uma forma compreensível e acessivel;

f) Confiabilidade: as informações e os processos utilizados na preparação do relatório deverão ser aplicados de forma que estabeleçam qualidade e materialidade das informações.

Considerando a importância destes princípios a GRI (2006) descreveu também em suas diretrizes testes para verificar se estes princípios estão sendo cumpridos:

Quadro 3: Testes sugeridos para a verificação da aderência aos princípios determinados

\begin{tabular}{|c|c|}
\hline Princípio & Teste \\
\hline Equilíbrio & $\begin{array}{l}\text { - O relatório divulga resultados e temas tanto favoráveis quanto desfavoráveis. } \\
\text { - As informações são apresentadas num formato que permite aos usuários ver } \\
\text { tendências positivas e negativas no desempenho de ano para ano; } \\
\text { - A ênfase em diferentes temas do relatório é proporcional à sua materialidade. }\end{array}$ \\
\hline & $\begin{array}{l}\text { - O relatório e as informações nele contidas podem ser comparados de um ano } \\
\text { para outro; } \\
\text { - O desempenho da organização pode ser comparado com padrões de } \\
\text { referência (benchmarks) apropriados; } \\
\text { - Qualquer variação significativa entre relatórios com respeito a limite, escopo, } \\
\text { duração do período analisado ou informações cobertas pode ser identificada e } \\
\text { explicada; } \\
\text { - O relatório utiliza, quando disponíveis, protocolos geralmente aceitos para } \\
\text { compilação, medição e apresentação de informações, incluindo os protocolos } \\
\text { técnicos da GRI para indicadores contidos nas Diretrizes; } \\
\text { - O relatório usa suplementos setoriais da GRI, quando disponíveis. }\end{array}$ \\
\hline
\end{tabular}




\begin{tabular}{|c|c|}
\hline Exatidão & $\begin{array}{l}\text { - O relatório indica quais dados foram medidos; } \\
\text { - As técnicas de medição de dados e as bases de cálculo são descritas } \\
\text { adequadamente e podem ser reproduzidas com resultados semelhantes; } \\
\text { - A margem de erro para dados quantitativos não é suficiente para influenciar } \\
\text { substancialmente a capacidade dos stakeholders de chegar a conclusões } \\
\text { adequadas e consistentes sobre o desempenho; } \\
\text { - O relatório indica quais dados foram estimados e que hipóteses e técnicas } \\
\text { foram usadas na elaboração dessas estimativas ou onde as informações } \\
\text { podem ser encontradas; } \\
\text { - As declarações qualitativas do relatório são válidas com base em outras } \\
\text { informações relatadas e em documentação disponível. }\end{array}$ \\
\hline Periodicidade & $\begin{array}{l}\text { - As informações constantes no relatório estão sendo divulgadas enquanto são } \\
\text { ainda recentes em relação ao período coberto pelo relatório; } \\
\text { - A coleta e a divulgação das informações fundamentais sobre o desempenho } \\
\text { são compatíveis com o cronograma dos relatórios de sustentabilidade; } \\
\text { - As informações constantes no relatório (incluindo os informes publicados via } \\
\text { internet) mostram claramente o período de tempo a que se referem, quando } \\
\text { serão atualizadas e quando foram feitas as últimas atualizações. }\end{array}$ \\
\hline Clareza & $\begin{array}{l}\text { - O relatório contém o nível necessário de informações para atender } \\
\text { às expectativas dos stakeholders, mas evita detalhes excessivos e } \\
\text { desnecessários; } \\
\text { - Os stakeholders podem encontrar as informações específicas que desejam } \\
\text { sem demasiado esforço, por meio de índices, mapas, links ou outras } \\
\text { ferramentas; } \\
\text { - O relatório evita vocabulário técnico, siglas, jargões e outros termos que } \\
\text { tendem a ser pouco conhecidos pelos stakeholders e inclui explicações } \\
\text { (quando necessário) na seção em questão ou num glossário; } \\
\text { - Os dados e informações do relatório estão disponíveis aos stakeholders, } \\
\text { inclusive aos que têm necessidades específicas de acessibilidade } \\
\text { (habilidades, idiomas e tecnologias diferentes). }\end{array}$ \\
\hline Confiabilidade & $\begin{array}{l}\text { - A abrangência da verificação externa está identificada; } \\
\text { - A fonte original das informações do relatório pode ser identificada pela } \\
\text { organização; } \\
\text { - A organização pode fornecer comprovações que embasam hipóteses ou } \\
\text { cálculos complexos; } \\
\text { - Encontra-se disponível uma declaração por parte de quem forneceu os dados } \\
\text { ou informações originais, atestando sua confiabilidade ou exatidão dentro de } \\
\text { margens de erro aceitáveis. }\end{array}$ \\
\hline
\end{tabular}

Fonte: Elaborado pelos autores a partir de GRI (2006).

Os princípios determinados pela GRI estão alinhados com as características para relatórios ambientais identificadas por Bebbington et al. (2021).

\section{PROCEDIMENTOS METODOLÓGICOS}

\subsection{Delineamento da pesquisa}

Quanto à abordagem, este estudo fundamenta-se na pesquisa qualitativa, a pesquisa qualitativa responde a questões muito particulares, preocupando-se com um nível de realidade que não pode ser quantificado (Minayo, 2001).

Quanto ao objeto, este estudo se classifica como uma pesquisa documental, segundo Gil (2007, p. 45), a pesquisa documental "vale-se de materiais que não receberam ainda um tratamento analítico, ou ainda podem ser reelaborados de acordo com os objetivos da pesquisa". Para atingir seu propósito por meio da análise 
documental, a pesquisa utilizou os relatórios de sustentabilidade da Usina Hidrelétrica Itaipu publicados no período de 2014 a 2019.

\subsection{Caracterização do estudo}

A Itaipu Binacional (também conhecida como Usina Hidrelétrica Itaipu) teve sua origem a partir de negociações diplomáticas entre o Brasil e o Paraguai. Em 1973 foi firmado o Tratado de Itaipu pelos governos dos dois países, este tratado criou e rege a entidade binacional Itaipu, uma empresa pertencente ao campo do direito público internacional (Itaipu Binacional, 2019a).

A Itaipu Binacional (2015) adota um modelo de gestão ambiental que tem como objetivo promover o uso sustentável dos recursos naturais ali presentes, fazendo a conexão dos aspectos energia, água, território e biodiversidade.

\subsection{Indicadores escolhidos}

Os indicadores da análise foram obtidos do conteúdo dos relatórios de sustentabilidade disponíveis pela Itaipu por meio do seu site, foram escolhidos apenas os indicadores ambientais abordados pelas empresas em seus relatórios. Devido ao seu ramo de atuação, o maior impacto ambiental da usina hidrelétrica ocorre no consumo de água e na fauna e flora da região onde está localizada (Terrin; Blanchet, 2019), escolhemos os seguintes indicadores:

a) G4-EN22 / 306-1 - Descarte total de água, por qualidade e destinação: este indicador evidencia a quantidade de água retirada, consumida e descartada por uma organização. A qualidade desses descartes pode afetar o funcionamento do ecossistema de várias maneiras, até impactos mais amplos sobre a qualidade de vida em uma área, incluindo consequências sociais e econômicas para comunidades locais e povos indígenas (GRI, 2018).

b) G4-EN10 / 303-3 - Percentual e volume total de água reciclada e reutilizada: Relate o volume total de água reciclada e reutilizada pela organização, a taxa de reutilização e reciclagem de água constitui uma medida de eficiência e demonstra o sucesso da organização na redução da retirada e descarte total de água (B3, 2021, p. 101).

c) G4-EN14 / 304-4 - Número Total de Espécies Incluídas na Lista Vermelha da IUCN: o indicador ajuda a organização a identificar onde suas atividades representam uma ameaça para espécies de plantas e animais já ameaçadas. Com essa identificação, é possível iniciar as etapas apropriadas para evitar danos e extinção de espécies (GRI, 2016).

d) G4-EN13 / 304-3- Habitats Protegidos ou Restaurados: representa "a extensão das atividades de prevenção e remediação de uma organização com respeito a seus impactos na biodiversidade. Essa divulgação refere-se a áreas onde a correção foi concluída ou onde a área está ativamente protegida" (GRI, 2016, p. 9).

Após a seleção dos indicadores escolhidos foi feita uma análise baseada nas diretrizes publicadas pela GRI (2006) para verificar o nível de aderência aos princípios determinados pela GRI que possuem como objetivo assegurar a qualidade da informação divulgada.

\subsection{Projetos escolhidos}

Para complementar a análise da evidenciação de informações ambientais selecionamos três projetos relacionados a gestão e consumo de água, e a preservação da fauna e flora da região: 
a) Gestão de Bacias Hidrográficas: o projeto busca planejar ações de forma a promover o desenvolvimento regional sustentável e o bom manejo dos recursos hídricos;

b) Monitoramento e Avaliação Ambiental: busca realizar diagnósticos e avaliações ambientais para que as águas se mantenham em boas condições para os usos múltiplos do reservatório;

c) Biodiversidade, nosso patrimônio: possui o objetivo de contribuir para a preservação, conservação e recuperação da flora e fauna regionais, valorizando a biodiversidade nas áreas protegidas e reservatório.

Os princípios determinados pela GRI não estão atrelados apenas aos indicadores ambientais, mas sim a todo o conteúdo do relatório. Desta forma, os projetos também estão englobados na análise por evidenciar o total de gastos com preservação ambiental.

\section{ANÁLISE DOS RESULTADOS}

\subsection{Verificação da aplicação dos princípios determinados pela GRI}

Os relatórios de sustentabilidade utilizados na análise estão disponíveis no site da Itaipu. A hidrelétrica realiza sua divulgação desde o ano de 2003 (Itaipu Binacional, 2019b). Esta parte da análise consiste em verificar se o conteúdo apresentado na parte "desempenho ambiental" dos relatórios da Itaipu condiz com os princípios determinados pela GRI e foi realizada por meio da escolha de um dos testes sugeridos pela GRI (2006).

Para cada princípio, será verificado se a edição do relatório está condizente com a determinação da GRI. Caso a edição do relatório tenha um desempenho positivo em relação ao teste será marcado com "X", caso seja negativo será marcado com "-". Para o teste foi levado em consideração os indicadores e projetos selecionados.

Quadro 4: Testes de verificação dos princípios aplicados a evidenciação dos indicadores e projetos selecionados

\begin{tabular}{|l|l|c|c|c|c|c|c|}
\hline \multicolumn{1}{|c|}{ Princípio } & \multicolumn{1}{|c|}{ Teste escolhido } & 2014 & 2015 & 2016 & 2017 & 2018 & 2019 \\
\hline Equilíbrio & $\begin{array}{l}\text { O relatório divulga resultados e } \\
\text { temas tanto favoráveis quanto } \\
\text { desfavoráveis. }\end{array}$ & $\mathrm{X}$ & $\mathrm{X}$ & $\mathrm{X}$ & $\mathrm{X}$ & $\mathrm{X}$ & $\mathrm{X}$ \\
\hline Comparabilidade & $\begin{array}{l}\text { O relatório e as informações nele } \\
\text { contidas podem ser comparados } \\
\text { de um ano para outro. }\end{array}$ & $\mathrm{X}$ & $\mathrm{X}$ & - & - & - & - \\
\hline Exatidão & $\begin{array}{l}\text { As declarações qualitativas do } \\
\text { relatório são válidas com base em } \\
\text { outras informações relatadas e } \\
\text { em documentação disponível. }\end{array}$ & $\mathrm{l}$ & $\mathrm{X}$ & $\mathrm{X}$ & $\mathrm{X}$ & $\mathrm{X}$ & $\mathrm{X}$ \\
\hline Periodicidade & $\begin{array}{l}\text { As informações constantes no } \\
\text { relatório estão sendo divulgadas } \\
\text { enquanto são ainda recentes em } \\
\text { relação ao período coberto pelo } \\
\text { relatório. }\end{array}$ & $\mathrm{X}$ & $\mathrm{X}$ & $\mathrm{X}$ & $\mathrm{X}$ & $\mathrm{X}$ & $\mathrm{X}$ \\
\hline
\end{tabular}




\begin{tabular}{|l|l|l|l|l|l|l|l|}
\hline Clareza & $\begin{array}{l}\text { Os stakeholders podem encontrar } \\
\text { as informações especificas que } \\
\text { desejam sem demasiado esforço, } \\
\text { por meio de índices, mapas, links } \\
\text { ou outras ferramentas. }\end{array}$ & $\mathrm{X}$ & $\mathrm{X}$ & $\mathrm{X}$ & $\mathrm{X}$ & $\mathrm{X}$ & $\mathrm{X}$ \\
\hline Confiabilidade & $\begin{array}{l}\text { A abrangência da verificação } \\
\text { externa está identificada; }\end{array}$ & $\mathrm{X}$ & $\mathrm{X}$ & $\mathrm{X}$ & $\mathrm{X}$ & $\mathrm{X}$ & $\mathrm{X}$ \\
\hline
\end{tabular}

Fonte: Elaboração própria com base nos dados da pesquisa.

A apresentação geral do conteúdo do relatório deve retratar de modo imparcial o desempenho da organização, para alcançar este objetivo, o conteúdo do relatório deve possuir aderência ao princípio "Equilíbrio" (GRI, 2006), durante a análise foi possível verificar ao realizar uma leitura das cinco edições que quando um indicador possui um resultado negativo o mesmo é divulgado, e costuma haver um breve comentário sobre o que levou a este resultado.

Apesar da divulgação do resultado negativo, é possível notar que o desempenho positivo costuma receber uma ênfase maior, comportamento já observado no estudo feito por Mota, Mazza e Oliveira (2011) e também por Bebbington et al. (2021).

A "Comparabilidade" é de grande importância para a avaliação de desempenho, pois os stakeholders que usarem o relatório deverão poder comparar as informações sobre o atual desempenho da organização com o anterior (GRI, 2006).

O princípio foi seguido parcialmente durante o período analisado, foi possível comparar as informações sobre o desempenho atual com o anterior dos indicadores G4-EN22, G4EN13 e G4-EN14 ao longo das seis edições, é importante destacar que o indicador G4EN10 é omitido das edições de 2016 e 2017, voltando a aparecer novamente na edição de 2018 em diante, não há explicação para a omissão do indicador nas edições mencionadas.

Durante as edições de 2014 a 2016 foi possível identificar os valores investidos nos projetos ambientais selecionados, no entanto, isto não é possível no relatório de 2018 e 2019, onde não foram divulgadas informações a respeito dos valores investidos nos projetos. O desempenho positivo obtido nestes projetos foi comentado, mas o motivo da não divulgação dos valores investidos não foi explicado. O descumprimento deste princípio também foi apontado no estudo feito por Mota, Mazza e Oliveira (2011, p. 78) ao identificar que "percebeu-se que as empresas não seguem alguns princípios das linhas gerais da GRI como a comparabilidade" e que "os resultados positivos são mais enfáticos em suas conquistas". A falta da capacidade da comparabilidade prejudica a interpretação do leitor sobre o relatório (Bebbington et al., 2021, Mota, Mazza e Oliveira, 2011).

As informações qualitativas sobre o desempenho dos indicadores costumam ser acompanhadas por informações quantitativas, sendo possível considerar que as cinco edições analisadas cumprem com o princípio "Exatidão". Os relatórios da Itaipu são publicados regularmente desde 2003, mostrando o período a que se referem e as informações são recentes em relação ao período abrangido pelo relatório, portanto o princípio "Periodicidade" é seguido durante todas as edições analisadas. 
A “Clareza" é um princípio presente em todas as edições analisadas, verifica-se isso, pois as informações estão disponíveis de forma acessível e organizada através dos índices, links, tabelas e outras ferramentas visuais. Quanto ao acesso a ferramentas específicas de acessibilidade (habilidades, idiomas e tecnologias diferentes), os relatórios divulgados estão disponibilizados nos idiomas inglês e espanhol, além do português.

O princípio "Confiabilidade" é fundamental para que os stakeholders tenham certeza de que as informações que compõem o relatório foram verificadas para que se estabeleça confiabilidade de seu conteúdo e se saiba até que ponto os princípios de relatório da GRI foram aplicados. A Itaipu assegura a integridade das informações contidas no conteúdo do seu relatório como um todo através de auditoria independente, a verificação externa foi feita pela KPMG no período de 2014 - 2019.

A auditoria realizada concluiu que com base nos procedimentos realizados, descritos no relatório, não houve evidências que levassem a acreditar que as informações constantes nos relatórios de sustentabilidade não tenham sido compiladas de acordo com os registros e arquivos que serviram de base para a sua preparação (Itaipu Binacional, 2015, 2016, 2017, 2018, 2019, 2020).

A verificação externa pode ser realizada individualmente sobre os indicadores, ao final do relatório é informado quais indicadores passaram por validação externa, entre os indicadores escolhidos para a análise da validação individual variou durante as edições. O indicador G4-EN22 passou por verificação externa nas edições de 2015, 2016, 2017 300 e 2018, G4-EN14 em 2014, 2016, 2017, 2018, 2019, G4-EN13 em 2015, 2016 e 2017, o indicador G4-EN10 não passou por verificação externa em nenhuma edição analisada.

Com relação à aderência aos princípios determinados pela GRI é possível perceber que a Itaipu busca manter-se alinhada através da publicação regular de seus relatórios de sustentabilidade, divulgação da informação de forma clara e objetiva, e através da verificação externa do relatório como um todo.

Entretanto, os relatórios analisados apresentam algumas falhas já observadas em outros estudos (Bebbington et al., 2021, Mota, Mazza \& Oliveira, 2011, Sucena \& Marinho, 2019), como a omissão de informações de um relatório para o outro, ênfase maior no desempenho positivo do que no desempenho negativo, falta de justificativa para a omissão de informações de um ano para outro. Essas falhas permitem observar também o comportamento que organizações tendem a utilizar os relatórios de sustentabilidade para melhorar sua reputação e, por consequência, omitir informações que não considerem favoráveis (Bebbington et al., 2021).

\section{CONSIDERAÇÕES FINAIS}

Esta pesquisa teve por objetivo avaliar a qualidade da evidenciação ambiental praticada nos relatórios de sustentabilidade da Usina Hidrelétrica Binacional Itaipu, através da verificação da aderência aos princípios apresentados pela GRI para a elaboração do relatório com o conteúdo dos relatórios divulgados pela Itaipu. Considerando seu objetivo, 
esta pesquisa diferencia-se por buscar verificar a qualidade das informações divulgadas no relatório.

A busca pela responsabilidade ambiental da usina hidrelétrica Itaipu fica evidente em sua missão, visão, valores, razão pela qual a publicação de relatórios de sustentabilidade pode ser considerada uma excelente forma de evidenciar seu desempenho ambiental para os stakeholders.

A padronização e diretrizes da GRI buscam fornecer informações com qualidade e transparência para os leitores dos relatórios, apesar dessas determinações, a Itaipu apresentou falhas quanto a aderência ao princípio "comparabilidade", ao omitir informação sobre os valores investidos nos projetos analisados, a leitura do stakeholderfica prejudicada, pois não é possível visualizar tendências e comparar o desempenho dos projetos com períodos anteriores e outras organizações.

Entretanto, é possível identificar que a Itaipu buscou manter-se alinhada com os demais princípios analisados, os relatórios são publicados regularmente, as informações são divulgadas de forma clara e objetiva, possuindo três opções de idioma para a apresentação do relatório, e foi possível identificar verificação do conteúdo como um todo por parte de auditoria externa.

Como sugestão para novos estudos, esta pesquisa poderia ser replicada contemplando, se possível, uma maior quantidade de indicadores ambientais para análise e realizar uma comparação entre o nível de aderência às diretrizes da GRI com outras empresas do mesmo segmento, assim como avaliar também as informações quantitativas divulgadas no relatório.

\section{REFERÊNCIAS}

Bebbington, J., Larrinaga, C., O'dwyer, B., \& Thomson, I. (2021). Routledge handbook of environmental accounting. London: Routledge, Taylor \& Francis Group, Earthscan from Routledge.

Brundtland, G. H. (1991). Nosso futuro comum. Rio de Janeiro: Editora da Fundação Getúlio Vargas.

B3. G4: Diretrizes para relato de sustentabilidade. https://www.b3.com.br/data/files/ F7/07/8C/C9/5B243510DF0CA135790D8AA8/GRI-G4-Manual-de-Implementacao.pdf.

Ferreira, A. C. S. (2011). Contabilidade ambiental: Uma informação para o desenvolvimento sustentável. ( $3^{\mathrm{a}}$ ed.). Atlas.

Gaudencio, L., Oliveira, R., Curi, W., Santana, C., Silva, J. \& Meira, C. (2020). Oil and gas companies operating in Brazil adhere to GRI-G4 essential sustainability indicators: a critical review. Environment, Development and Sustainability.

Gil, A. C. (2007). Como elaborar projetos de pesquisa. Atlas.

Gray, R. H. \& Bebbington, J. (2001). Accounting for the environment. Sage.

Global Reporting Initiative (2006). Diretrizes para relatório de sustentabilidade: 2000-2006. https://www.ipai.pt/fotos/gca/g3_pobr_rg_final_with_cover_1271097860.pdf. 
Global Reporting Initiative. GRI 304: Biodiversity. https://www.globalreporting.org/standards/ gri-standards-download-center/?g=d711bdff-4da2-44c2-80f3-f9a7ee5db1f5.

Global Reporting Initiative. (2018) GRI 303:Waterand Effluents 2018. https://www.globalreporting. org/standards/gri-standards-download-center/?g=d711bdff-4da2-44c2-80f3-f9a7ee5db1f5.

Global Reporting Initiative. Mapping G4 to the GRI Standards - Disclosures - Full overview. https://www.globalreporting.org/standards/media/1098/mapping-g4-to-the-gristandards-disclosures-full-overview.pdf.

Igarashi, D. C. C., Igarashi, W., Lima, E. C., Dalbello, L., Hercos Junior, J. B. (2010). Análise do alinhamento entre o balanço social e o relatório de sustentabilidade dos três maiores bancos em atividade no Brasil. Contexto - Revista do Programa de Pós-Graduação em Controladoria e Contabilidade da UFRGS, 10(18), 34-48.

Itaipu Binacional. Nossa História. https://www.itaipu.gov.br/nossahistoria.

Itaipu Binacional. (2019). Relatórios de sustentabilidade. https://www.itaipu.gov.br/ responsabilidade/relatorios-de-sustentabilidade.

Itaipu Binacional. (2015) Relatórios de sustentabilidade. Foz do Iguaçu, 2015. https://www. itaipu.gov.br/sites/default/files/RS-2014-Port-2.pdf.

Itaipu Binacional. (2016). Relatórios de sustentabilidade. Foz do Iguaçu, https://www.itaipu. gov.br/sites/default/files/RS2015_180816_comseloGRI.pdf.

Itaipu Binacional. (2017). Relatórios de sustentabilidade. Foz do Iguaçu. https://www.itaipu. gov.br/sites/default/files/RS2016.pdf.

Itaipu Binacional. (2018). Relatórios de sustentabilidade. Foz do Iguaçu. https://www.itaipu. gov.br/sites/default/files/RS2017.pdf.

Itaipu Binacional. (2019). Relatórios de sustentabilidade 2018. Foz do Iguaçu. https://www. itaipu.gov.br/sites/default/files/RS2018_web.pdf .

Itaipu Binacional. (2020). Caderno de Indicadores Itaipu 2019. Foz do Iguaçu, https://www. itaipu.gov.br/sites/default/files/af_df/vf_CI_IB_2019_VERSAO_SITE.pdf .

Minayo, M. C. (Org.). (2001). Pesquisa Social: Teoria, método e criatividade. Editora Vozes. Mota, M. O., Mazza, A. C. A., Oliveira, F. C. (2013). Uma análise dos relatórios de sustentabilidade no âmbito ambiental do Brasil: sustentabilidade ou camuflagem? BASE - Revista de Administração e Contabilidade da UNISINOS, 10(1), 68-80.

Oliveira, M. C., Damasceno, F. A. M, Amorim, S. M. S. S., \& Gomes, C. A. S. (2020). Análise da Divulgação de Informações Ambientais por Empresas do Setor Elétrico: um Estudo em Empresas dos Países do Brics. Sociedade, Contabilidade e Gestão,15, (3), 65-83.

Queiroz, R. D., Grassi, P. Lazzare, K., Koppe, E., Tartas, B. R., \& Kemerich, P. (2013). Geração de energia elétrica através da energia hidráulica e seus impactos ambientais. Revista Eletrônica em Gestão, Educação e Tecnologia Ambiental.13(13), 2774-2784. 
Romeiro,A. R. (2012). Desenvolvimento sustentável: uma perspectiva econômico-ecológica. Estudos Avançados, 26(74), 65-92.

Silva, R. C. F., Seibert, R. M., Juliani, L. I., \& Wbatuba, B. B. R. (2018). Análise da Evidenciação Ambiental nas Corporações Brasileiras de Alto Impacto Ambiental Listadas na BMF \& Bovespa. Revista de Gestão e Secretariado, 9(3), 46-71.

Sucena, E., \& Marinho, M. M. O. (2019). Environmental disclosure analysis of sustainability reports the Brazilian and international brewing industry based on Global Reporting Initiative - GRI. Gestão \& Produção, v. 26, (3), e3120.

Terrin, K. A. P., \& Blanchet, L. A. (2019, dez). Direito de energia e sustentabilidade: uma análise dos impactos negativos das usinas hidrelétricas no Brasil. Revista Videre, [S.I.], 11(22), 47-63.

Tinoco, J. E. P., \& Kraemer, M. (2011). Contabilidade e Gestão ambiental. (3ª ed.). São Paulo: Atlas.

Tinoco, J. E. P, \& Robles, L. T. (2006). A contabilidade da gestão ambiental e sua dimensão para a transparência empresarial: estudo de caso de quatro empresas brasileiras com atuação global. Revista de Administração Pública, 40(6), 1077-1096.

\section{Dados dos autores:}

\section{Regiane Valejo Maciel}

(D) ORCID: https://orcid.org/0000-0001-8021-8330

Graduada em Ciências Contábeis pela Universidade Estadual de Mato Grosso do Sul. Ponta Porã, Mato Grosso do Sul, Brasil. E-mail: regianevalejomaciel@gmail.com.

\section{Carlos Jaelso Albanese Chaves}

DD. ORCID: https://orcid.org/0000-0001-8417-8778

Doutor em Administração. Professor da Universidade Estadual de Mato Grosso do Sul (UEMS). Ponta Porã, Mato Grosso do Sul, Brasil. E-mail: Jaelso.chaves@hotmail.com.

\section{Giuliano Oliveira de Macedo}

[D. ORCID: https://orcid.org/0000-0001-5431-7909

Graduado em Ciência da Computação pela Universidade Federal de Mato Grosso do Sul. Ponta Porã, Mato Grosso do Sul, Brasil. E-mail: giuliano.programador@gmail.com.

\section{Como citar este artigo:}

Maciel, R. V., Chaves, C. J. A., \& Macedo, G. O. (2021). Evidenciação Ambiental: uma análise dos relatórios de sustentabilidade da Usina Hidrelétrica Itaipu com base na Global Reporting Initiative - GRI. AOS - Amazônia, Organizações e Sustentabilidade, 10(2). http://dx.doi.org/10.17648/aos.v10i2.2317 